\title{
A IMPORTÂNCIA DA SEMIÓTICA APLICADA NA MARCA DE VAREJO
}

\section{The importance of semiotics applied in brand retail}

\section{La importancia de la semiótica aplicada en la marca comercial}

\author{
Flávia Cristina Martins Mendes ${ }^{1}$
}

\section{Resumo}

O artigo pretende mostrar a importância da aplicação da semiótica de Peirce para a compreensão da marca institucional de duas empresas do varejo. Como referencial teórico foi utilizado Lucia Santaella sobre semiótica, os conceitos de marca de Clotilde Perez e Kevin Keller e os conceitos de triângulo da marca Paulo de Lencastre e Ana Corte-Real. O foco é compreender os conceitos da semiótica peirceana dentro do triângulo da marca para analisar programa de reciclagem de lixo por meio dos relatórios de sustentabilidade.

Palavras-chave: semiótica, varejo, marca, reciclagem.

\begin{abstract}
The article highlights the importance of applying Peirce's semiotics to understand the corporate brand of two retail companies. It was used as a theoretical Lucia Santaella on semiotics, the concepts of brand of Clotilde Perez and Kevin Keller and the concepts of triangle brand of Paul Lancaster and Ana Corte-Real. The focus is to understand the concepts of Peircean semiotics in the triangle trademark review program to recycle waste through sustainability reporting.
\end{abstract}

Keywords: semiotics, retail, brand, recycling.

\section{Resumen}

El artículo destaca la importancia de la aplicación de la semiótica de Peirce para comprender la marca corporativa de ambas compañías al por menor. Fue utilizado como un teórico Lucía Santaella en la semiótica, los conceptos de la marca Clotilde Pérez y Kevin Keller y los conceptos de triángulo de la marca Lancaster Pablo y Ana Corte Real. El

\footnotetext{
${ }^{1}$ Mestranda em Ciências da Comunicação da ECA - USP e especialista em Comunicação Empresarial/Relações Públicas pela Faculdade Cásper Líbero, oito anos de experiência profissional na área de comunicação institucional e marketing.
} 
A importância da semiótica aplicada na marca de varejo

de Flávia Cristina Martins Mendes

objetivo es entender los conceptos de la semiótica peircena en el programa de marcas de revisión triángulo de reciclado de residuos a través de informes de sostenibilidad.

Palabras-clave: semiótica, al por menor, marca, reciclaje.

\section{INTRODUÇÃO}

O artigo é um trabalho de síntese que pretende dialogar com o tema da influência da sustentabilidade na gestão da marca institucional de empresas do varejo nacional.

A sustentabilidade tem se mostrado um tema complexo e abrangente na sociedade do século XXI. Esta foi a primeira contestação utilizada para a definição do objeto do artigo e também para verificar como se encontra o varejo nacional e como está sendo absorvida e implementada na sua identidade corporativa, pois a sustentabilidade ainda está em processo de construção dentro das organizações.

Afinal, os conceitos de sustentabilidade na tríplice aliança entre desenvolvimento econômico, social e ambiental, muitas vezes, são contrários aos princípios do varejo, como exemplo o consumo exacerbado tão valorizado por esta categoria e do qual depende e foi configurada a sua estrutura de negócio.

Muitas empresas começaram a associar seus produtos a sua imagem e marca para conseguir destaque num mercado denominado global e sem diferenciação.

"A vantagem competitiva surge fundamentalmente do valor que uma empresa consegue criar para seus compradores e que ultrapassa o custo de fabricação pela empresa". (Porter,1989:2)

Ao perceberem o conceito de vantagem competitiva, as empresas começaram a utilizar a sustentabilidade e a responsabilidade social corporativa como uma maneira de diferenciar-se de seus concorrentes, pois este tema ainda é recente e mal compreendido pela população.

O varejo tem uma estrutura de negócios bem específica, pois necessita gerenciar produtos e marcas de outras empresas e presta serviços em nome de sua própria marca.

O varejo inclui todas as atividades relativas à venda de produtos ou serviços diretamente ao consumidor final, para uso pessoal e não comercial. Um varejista ou uma loja de varejo é qualquer empreendimento comercial cujo faturamento provenha principalmente da venda de pequenos lotes no varejo. (Kotler \& Keller, 2006:500) 
Segundo David Rachman (1973), o varejo possui aspectos controláveis e incontroláveis. Dentro dos aspectos controláveis encontram-se o composto de bens e serviços, de distribuição e da comunicação. No aspecto incontrolável estão o consumidor, a concorrência, as condições econômicas e pressões legais e sociais.

Grandes varejistas como supermercados possuem uma enorme quantidade de produtos e muitas vezes o aspecto que é controlável pode tornar-se incontrolável quando esse tipo de empresa precisa gerenciar várias marcas e ainda ser sustentável, pois este gerenciamento parte de princípios muitas vezes intangíveis.

As empresas de varejo aqui apresentadas são os supermercados Walmart e Pão de Açúcar. O foco do artigo será como estas empresas associam a sua marca institucional, muitas vezes incontrolável, ao processo de reciclagem que está intrinsecamente ligado ao consumo consciente e tem como direção a interpretação semiótica de Pierce, a partir de Lucia Santaella.

Neste artigo o processo de divulgação das ações de reciclagem realizado pelas duas empresas será analisado por meio dos relatórios disponíveis nos respectivos sites, visto que foi a forma mais acessível para encontrar este tipo de informação e também a forma de comunicação institucional oficial.

\section{CONCEITOS DE MARCA}

Primeiramente para entender a importância da semiótica aplicada na gestão da marca é necessário mostrar os principais conceitos de marca.

A autora Clotilde Perez (2004:10) denomina a marca como "uma conexão simbólica e afetiva estabelecida entre uma organização, sua oferta material, intangível e aspiracional e as pessoas para quais se destina".

Ambos os autores Clotilde Perez e Kevin Keller priorizam que a marca está completamente envolvida com os consumidores ou com as pessoas interessadas. E que a marca não se define sem esse público.

"Uma marca é uma entidade perceptiva com raízes na realidade, mas também é mais do que isso, pois reflete as percepções e idiossincrasias dos consumidores." (Keller \& Machado, 2005:10)

A marca é a forma mais prática de se associar ou reconhecer um produto ou serviço. Os produtos e serviços, principalmente dentro do varejo, tornaram-se commodities, ou seja, não existe muita diferenciação de um produto ou serviço para o outro, muitas 
vezes a diferença é apenas pelo preço, mas esse quesito não tem sido mais tão valorizado quanto foi em outras épocas.

Os consumidores procuram algo maior aos escolher as suas marcas preferidas:

“A personalidade da marca reflete como as pessoas se sentem em relação a ela como resultado do que pensam que marca é ou faz, de como é comercializada e promovida etc." (Keller \& Machado, 2005:53)

A marca está inserida na cultura da sociedade nos dias atuais não apenas como forma de consumo, e sim como um contexto cultural e psicológico complexo.

\begin{abstract}
As marcas se expressam por meio do nome que apresentam, do logotipo, da forma e do design dos produtos que encarnam, da embalagem e do rótulo, da cor, do slogan, do jingle, da personalidade, do personagem que representa, de um mascote, além de outros recursos $e$ do contexto organizacional, envolvendo os funcionários e os parceiros e suas relações com o meio social. A utilização de uma ou outra forma de expressão depende do tipo do produto, de consumidor e dos objetivos organizacionais. (Perez, 2004:47)
\end{abstract}

Os conceitos de marca expostos apenas mostram a amplitude de associação da marca. Em uma empresa de varejo, principalmente em um supermercado, essa associação aumenta de tamanho e é por isso que este tipo de empresa começou a valorizar a sua marca como instituição e porque a mesma tinha poucos atributos, a sustentabilidade foi destacada.

A marca pode ser analisada de várias formas, muitos autores criaram modelos de análise e avaliação de marcas, um exemplo desse modelo é a Pirâmide do Brand Equity, criada por Kevin Keller (2005).

Muitos autores e estudiosos de branding também utilizam a semiótica peirceana para estudar as características e funções da marca.

\title{
3. A SEMIÓTICA DE PEIRCE E O TRIÂNGULO DA MARCA
}

Em 2007, Paulo de Lencastre e Ana Corte-Real escreveram um artigo para a Revista Organicom sobre a utilização do triângulo da marca para evitar a branding myopia que seria a visão da marca em apenas um aspecto ou sentido e isso é chamado de miopia porque não se vê a marca na sua amplitude máxima.

Os autores baseiam-se nos conceitos da semiótica de Peirce para construir o triângulo da marca.

As diversas facetas que a análise semiótica apresenta podem assim nos levar a compreender qual é a natureza e quais são os poderes de referência dos signos, que 
informação transmitem, como eles se estruturam em sistemas, como funcionam, como são emitidos, produzidos, utilizados e que tipos de efeitos são capazes de provocar no receptor. (Santaella, 2004:4)

Essas principais características da semiótica serão mostradas ao longo do artigo de uma forma generalizada e associadas ao relatório das ações de reciclagem do Walmart e Pão de Açúcar.

A semiótica procura avaliar a potencialidade do signo independente da intencionalidade da produção de sentido.

Segundo Lucia Santaella (2004:8),

A divisão triádica peirceana corresponde ao signo que é qualquer coisa de qualquer espécie e que representa outra coisa, chamada de objeto do signo, e que produz um efeito interpretativo em uma mente real ou potencial, esse efeito é chamado de interpretante do signo.

Neste trabalho, o signo corresponde ao relatório de sustentabilidade das empresas analisadas, objeto do signo imediato compreende o recorte da descrição das ações de reciclagem no mesmo relatório e o interpretante do signo o efeito da campanha na marca institucional e consequentemente nos públicos-alvos.

A mesma autora afirma que para Peirce as coisas precisam de três propriedades para ter capacidade de funcionar como signo. Essas propriedades são o quali-signo, uma qualidade que é um signo, o sin-signo sua propriedade de existir e ser um signo e por último, o legi-signo que é a propriedade com seu caráter de lei.

"Essas propriedades não são excludentes. Na maior parte das vezes, operam juntas, pois a lei incorpora o singular nas suas réplicas, e todo singular é sempre um compósito de qualidades." (Santaella, 2004:14)

O signo também se relaciona com o objeto, neste caso, a relação do que mostra o relatório de sustentabilidade com o que mostra a parte que se refere à reciclagem de lixo.

Independente das diferenças dos dois relatórios, o quali-signo, em ambos, seria o próprio relatório, a forma escrita de se expor algo, o sin-signo, a sua singularidade ou olhar observacional, seria o conteúdo, o que realmente cada relatório propõe e expõe de suas ações de reciclagem e o legi-signo é forma diferenciada, ou a lei, que cada relatório segue para informar de maneira particular o seu conteúdo.

Para confirmar estes pressupostos, Santaella (2004:32) descreve: "o que deve ser compreendido nesse passo da análise é que os sin-signos dão corpo aos quali-signos enquanto os legi-signos funcionam como princípios-guias para os sin-signos." 
A relação signo e objeto vai mais além porque o signo tem dois objetos: objeto dinâmico e objeto imediato.

“O objeto imediato [...] é o modo pelo qual aquilo que o signo representa está, de alguma maneira e em certa medida, presente no próprio signo" (Santaella, 2004:34). Este objeto liga-se as três propriedades citadas anteriormente.

Já o "objeto dinâmico é o que determina o signo, mas depende do objeto imediato e existem três modos dos signos se reportarem a esse objeto" (Santaella, 2004:36). O modo icônico do qual dependem de um campo associativo por similaridade, o modo indicial, como uma forma de vestígios, traços e referências e o modo simbólico que tem sua base nas convenções culturais, na semiose humana e referências de costumes e valores coletivos e de padrões estéticos, comportamentais, expectativas sociais etc.

A marca de uma empresa, principalmente quando denota a instituição, faz a relação signo e objeto destacar-se pelo modo simbólico. Não são descartados os outros dois modos, mas a marca institucional está muito arraigada aos valores coletivos da sociedade em que se encontra e das expectativas dessa mesma sociedade.

Então, a marca institucional encontra nessas expectativas uma maneira de se destacar e de se valorizar perante outros concorrentes. No varejo brasileiro de supermercados essa concorrência é ainda mais acirrada.

Não é apenas da relação com o objeto que o signo se impõe, há também a relação com o interpretante. "O interpretante imediato que é interno e pertence ao signo, o interpretante dinâmico o qual se refere ao efeito que o signo realmente produz e o interpretante final que se refere ao resultado o qual todo intérprete deveria chegar". (Santaella, 2004:38)

Ao se construir um signo obviamente se quer um resultado. Dentro das organizações isso é primordial, pois tudo que é criado tem a intenção de obter bons resultados. Os relatórios de sustentabilidade são conhecidos há pouco tempo e, portanto tem pouca disseminação.

Como são pouco conhecidos, esses relatórios ainda geram confusão do qual deve ser seu conteúdo e para quem se deve divulgar.

Alguns dos conceitos apresentados da semiótica de Peirce podem ser utilizados para compreender melhor a função desses importantes relatórios organizacionais na consolidação da marca institucional do varejo. 
A importância da semiótica aplicada na marca de varejo

de Flávia Cristina Martins Mendes

Conforme foi citado anteriormente, Paulo de Lencastre e Ana Corte-Real provam, por meio do triângulo da marca, que a semiótica peirceana é essencial para analisar uma marca.

Pela concepção triádica expõem um modelo descritivo da marca em três pilares fundamentais: o pilar da identidade, o pilar da do objeto e o pilar do mercado. (Lencastre \& Corte-Real, 2007:105)

O primeiro é o pilar da identidade e compõe o identity mix, significado jurídico da marca. E existem três níveis: identidade central (sinal da marca ou nome), identidade efetiva (expressões gráficas como letras, desenhos e cores) e identidade ampliada (sinais suscetíveis de proteção jurídica e o manual de identidade corporativa). O brand mix também compõe este pilar e caracteriza por a marca encontrar-se associada à estrutura da identidade corporativa

O segundo pilar é designado como pilar do objeto onde se encontram o marketing mix e product mix. Os autores denominam como objeto a organização, a pessoa física ou jurídica que o nome da marca identifica.

Os três níveis de marketing mix são: o produto central (o produto em si), o produto efetivo (quais as atividades empresariais a marca se associa) e o produto ampliado (o marketing mix específico para cada público), no mesmo esquema que aparece do identity mix.

Já o product mix corresponde ao conjunto de relações de troca com cada um dos seus diferentes públicos.

O último pilar é o pilar do mercado e compõe o response mix e o public mix. Segue o conceito de interpretante de Peirce e ao transpor para a marca o interpretante é o mercado.

Os níveis do response mix são: a resposta central voltada ao que se chama de top of mind da marca, a resposta efetiva designa à imagem da marca, pois neste ponto já surge uma interação mais real e a resposta ampliada é o valor da marca, seu legítimo significado. O public mix refere-se aos diferentes públicos: clientes, funcionários, acionistas, fornecedores etc.

Todos esses conceitos apresentados serão utilizados para identificar a associação da marca institucional com os relatórios de sustentabilidade na parte de reciclagem de lixo.

Primeiramente foi necessário verificar alguns pontos dos relatórios antes de partir para a análise propriamente dita. 


\section{ESPECIFICAÇÕES DE CADA RELATÓRIO}

O Walmart ${ }^{2}$ é uma empresa do varejo que iniciou em 1962 no estado do Arkansas nos Estados Unidos como uma loja de descontos. No Brasil começou suas operações em 1995 e encontra-se presente em 18 estados do Nordeste, Centro-Oeste, Sudeste e Sul.

Para entrar na era da sustentabilidade a empresa criou a campanha Pacto pela Sustentabilidade que se iniciou em junho de 2009 com um encontro com 300 fornecedores e representantes e 200 ONGs.

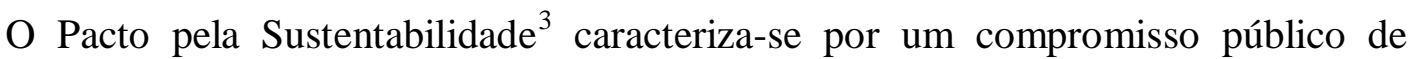
desenvolvimento sustentável da Amazônia, redução de embalagens e desenvolvimento de cadeias produtivas mais sustentáveis.

Os pontos principais do pacto são desenvolvidos e detalhados em três relatórios chamados de Diálogos para a Sustentabilidade que mostram as ações da empresa.

No último relatório, chamado de Embalagens, a empresa mostra que um terço do lixo doméstico é composto por embalagens e que diariamente vinte e cinco mil toneladas apenas de embalagens vão para os lixões. Este relatório exibe pontos específicos sobre o que são produtos recicláveis e como se realiza a coleta seletiva de lixo. Todos os relatórios apresentam uma introdução sobre o assunto antes de exibir quais são as ações realizadas.

A empresa informa que colocou em prática o programa Impacto Zero e visa à redução de $25 \%$ dos resíduos sólidos (sem informar período para a conclusão da ação) por meio do mapeamento das características de cada resíduo.

O relatório também mostra que o Walmart realiza ações conjuntas com outras empresas para estimular produtos de menor impacto ambiental, a exemplo do brinquedo jogo imobiliário sustentável da marca Estrela, onde quem joga não compra imóveis e, sim, créditos de carbono e utiliza em sua embalagem plástico verde (Tipo de plástico, biopolietileno, vindo de fontes renováveis, segundo o mesmo relatório) e papel certificado FSC (Forest Stewardship Council) ${ }^{4}$.

Outro ponto que o relatório destaca é a redução de sacolas plásticas que aparece como a única meta com prazo e deve reduzir em 50\% de sacolas até 2013.

\footnotetext{
${ }^{2}$ Disponível em <www.walmart.com.br>, Acesso em: 20/04/2010

${ }^{3}$ Disponível em <http://www.walmartbrasil.com.br/summit/pacto/>, Acesso em: 20/04/ 2010.

${ }^{4}$ Tipo de certificação internacional criada para atestar que o papel provém de área de reflorestamento e não de florestas nativas.
} 
No quesito reciclagem a empresa destaca a parceria do Instituto Walmart com o Instituto Coca-Cola e com o Cempre (Compromisso empresarial para a reciclagem) para criar estações de reciclagem e que estão presentes em 290 lojas da rede.

A outra empresa do varejo é o grupo Pão de Açúcar ${ }^{5}$ que iniciou em 1948 com a Doceira Pão de Açúcar por Valentim dos Santos Diniz, o “Sr. Santos”. A loja oferecia serviços de buffet e produtos artesanais. E em 1959 inaugurou o primeiro supermercado, o Pão de Açúcar.

Na década de 1980 o grupo inaugurou uma nova geração de hipermercados, o Extra que, com o fechamento das lojas Jumbo, tornou-se o único hipermercado da rede.

Em 2008, o grupo Pão de Açúcar lançou seu primeiro relatório de sustentabilidade ${ }^{6}$ baseado nos indicadores do GRI (Global Reporting Initiative) ${ }^{7}$.

No mesmo ano, o grupo começa com uma nova política de atuação em sustentabilidade caracterizada por três diretrizes: somar mais qualidade de vida, dividir com a comunidade e multiplicar a consciência de consumo.

A última diretriz que é o multiplicar a consciência de consumo tem como intuito mobilizar os colaboradores e os clientes para consumir com consciência, sem agredir o meio ambiente, reciclar o lixo, economizar energia e água e comprar produtos sustentáveis de pequenas organizações. As ações características são uso de sacolas retornáveis, a escola vai ao Extra onde ensinam crianças de escolas públicas e particulares a praticar o consumo consciente e reciclar lixo e o caixa verde onde é possível coletar embalagens pré-consumo.

O destaque para a disseminação da reciclagem são as estações de reciclagem.

Algumas ações em parceria com a empresa Unilever que conta com 110 estações espalhadas por todo o Brasil, o Extra $\mathrm{H} 2 \mathrm{OH}$ ! possui 78 estações de reciclagem, montadas em lojas de 26 municípios de 15 Estados brasileiros e no Distrito Federal.

Existem também estação de coleta de óleo de cozinha, em 20 lojas, do supermercado CompreBem.

Essas são as principais ações relatadas pelo relatório e que também se encontram detalhadas no site do grupo Pão de Açúcar com algumas atualizações de números.

No relatório do grupo Pão de Açúcar aparecem as ações de todas as bandeiras de supermercados da empresa, como exemplo Extra, CompreBem e a bandeira Pão de Açúcar.

\footnotetext{
${ }^{5}$ Disponível em <http://www.grupopaodeacucar.com.br>, Acesso em: 20/04/2010

${ }^{6}$ Disponível em <http://www.grupopaodeacucar.com.br>, Acesso em: 20/04/2010

${ }^{7}$ Indicador que auxilia, de forma gratuita e espontânea, as organizações a realizarem seus relatórios de sustentabilidade.
} 
Como o foco deste artigo são os relatórios e as ações de reciclagem, todas as marcas serão analisadas pela marca mãe que é o Pão de Açúcar.

\section{O TRIÂNGULO DA MARCA APLICADO NOS RELATÓRIOS}

Depois de mostrados os principais conceitos da semiótica e como estes são usados no triângulo da marca, o artigo pretende associar e verificar os pontos dos relatórios que se relacionam a marca institucional.

Como Lencastre e Corte-Real colocaram por meio do triângulo da marca, baseado na tríade de Peirce, a identidade estaria ligada ao signo, ou melhor, o que é a sua essência.

O signo nos dois relatórios é o próprio relatório de sustentabilidade, então nesta questão tanto a marca Pão de Açúcar como a marca Walmart expõem seus sinais de identidade como logotipo e grafia cada um a sua maneira.

O relatório do Walmart detalha a importância de se fazer reciclagem, como é realizada e o que são produtos recicláveis antes de descrever suas ações, aliás, o foco deste relatório é para elucidar o tema mais do que mostrar as ações de sustentabilidade e reciclagem.

No grupo Pão de Açúcar o foco é a própria empresa, aparecem mais detalhes de orçamento e da sua missão e dos seus valores, de como atua no mercado de varejo, quais são as bandeiras dos supermercados. A empresa procura colocar que o relatório é baseado no GRI (Global Reporting Initiative), ou seja, segue regras internacionais de elaboração de relatórios.

As duas organizações possuem logotipo azul, por isso os relatórios dão destaque a cores frias e principalmente a tons de azul. Elucidam os relatórios com fotos das ações da empresa como forma de confirmar a realidade e dar credibilidade.

O relatório do Walmart coloca gráficos em tons de azul para destacar os temas referentes à reciclagem como consumo de embalagens e coleta seletiva de lixo. Já o grupo Pão de Açúcar coloca gráficos com números da própria empresa em tons de verde, pois esta cor está associada ao meio ambiente, e muitas pessoas ainda consideram a sustentabilidade como algo relacionado apenas à conservação do planeta Terra.

Outro ponto que não se pode esquecer é que o logo do Pão de Açúcar aparece em todas as páginas escritas como forma de tentar não deixar o leitor esquecer-se de quem fez o relatório. O mesmo não acontece com a outra empresa, pois ela enfatiza a cor azul como forma de memorização da marca institucional da empresa. 
O pilar da identidade, neste caso, aparece sutilmente apesar de demonstrar pontos marcantes e que se distinguem, afinal, essa é a função da identidade corporativa, mostrar as qualidades e singularidades da marca e se diferenciar da outra empresa.

O segundo aspecto do triângulo é o pilar objeto que nos relatórios é o recorte da descrição das ações de reciclagem do mesmo relatório.

As informações do Walmart encontram-se em quatro páginas enquanto as do Pão de Açúcar encontram em duas páginas. As duas explicações são sucintas e breves.

O Walmart coloca como ação mais importante o programa Impacto Zero como forma de gerir resíduos sólidos o que seria uma ação prévia e de grande valia antes da reciclagem. Depois mostra as ações conjuntas com outras empresas (marcas) para vender produtos com embalagens mais sustentáveis e que ajudam neste programa. Por último informa a parceria com o Cempre e o Instituto Coca-Cola na criação de estações de reciclagem.

Ao colocar as ações de reciclagem nesta ordem de apresentação, a empresa procura exibir que seu objeto (a reciclagem) é mais amplo e engloba outras ações para acontecer, refere-se ao enlarged product (produto ampliado) do triângulo. A marca institucional está aqui, pelo menos na elaboração deste relatório, associada às ações com amplitude onde pretendem ir além do que é oferecido.

O Pão de Açúcar mostra o pilar do objeto de forma diferente. Coloca a reciclagem na parte do relatório chamada Outras áreas abrangendo geração de resíduos, uso de materiais e caixa de coleta de gordura. Enfatiza o pioneirismo no varejo com a criação de estações de reciclagem com parcerias com outras empresas e a quantidade de estações estabelecidas. Há também a informação sobre a reciclagem do óleo de cozinha e o caixa verde onde o consumidor descarta embalagens que não pretende usar após passar sua compra no caixa tradicional. Por colocarem apenas duas páginas com ilustrações, a empresa não evidencia o valor da reciclagem para uma empresa de varejo, apenas que utiliza esse tipo de ação, mas que o enfoque não é a reciclagem, e sim a marca institucional Pão de Açúcar dentro do contexto da sustentabilidade.

No último ponto da tríade, o pilar do mercado corresponde ao interpretante do signo que é o efeito da campanha na marca institucional e consequentemente nos públicos-alvos.

Transpondo para a marca, o interpretante é o mercado - do seu sentido mais restrito ao mais amplo - ou seja, a resposta (interpretação) que a marca tem junto de um determinado indivíduo (intérprete), e por extensão junto de um determinado público, entendido como conjunto de pessoas físicas ou jurídicas pertinentes para a marca pela relação de troca que representam. (Lencastre \& Corte-Real, 2007:109) 
O interessante é que algumas empresas do varejo de supermercado têm utilizado a sustentabilidade como uma forma de vantagem competitiva, e, portanto de diferenciação para a marca institucional.

A marca institucional Walmart divulgou primeiramente a sua consciência sobre a sustentabilidade, e essa consciência apareceu a poucos anos, em $2005 .^{8}$

Já o Pão de Açúcar vem trabalhando durante muitos anos com o assunto, principalmente no quesito estações de reciclagem, mas o grupo se perdeu com alterações de liderança e a sustentabilidade engloba varias ações, algumas delas nem estão ligadas as outras.

O core response (resposta central) ou top of mind fica para o Walmart que teve a capacidade de expor mais rapidamente e massivamente o assunto.

Quanto à actual response e a enlarged response, as duas empresas podem se considerar no mesmo patamar, porque possuem o mesmo erro ao disseminar sustentabilidade, ou seja, não conseguem compreender a real importância do assunto e transmitem isso de uma forma imprecisa, pelo menos na maneira oficial de divulgar suas ações, ou seja, nos relatórios de sustentabilidade.

\section{CONSIDERAÇÕES FINAIS}

Fiquei em casa sinceramente hibernando tambem, espero que nenhum escrupulo me impeça de transferir o dia oficial das calunias "inocentes" para um em que me apeteça.

Aqui foi apresentado de forma sucinta a aplicação do triângulo da marca na associação com relatórios de sustentabilidade.

As empresas de uma forma geral precisam, através da semiótica de Peirce, compreender que apesar de todo trabalho na elaboração desses relatórios, elas provavelmente não alcançam a resposta desejada dos seus interpretantes, pois elas mesmas não entendem o signo e o objeto que utilizam para associar à sua marca.

O signo e o objeto aqui nestes relatórios são apenas meios para a divulgação de uma ação de sustentabilidade, mas é necessário entender a relação do signo com seu objeto.

\footnotetext{
${ }^{8}$ Informação retirada do Guia Exame de Sustentabilidade, 2009.
} 
A importância da semiótica aplicada na marca de varejo

de Flávia Cristina Martins Mendes

Aqui surgem algumas dúvidas: Será que o quali-signo destes relatórios mostra a identidade da empresa? Será que o sin-signo, a singularidade de cada relatório, expõe fatos relevantes sobre o assunto? E ainda, será que o legi-signo em ambos não tem a mesma regra?

A identidade foi exposta de forma generalizada e essa não é a função da identidade. Já os fatos são importantes, mas as empresas demonstram não dar muita importância aos próprios fatos, pois elas se importam mais em citar as ações e não em desenvolver um relatório preciso, assim os fatos tornam-se triviais.

Os dois seguem a mesma regra, mesmo que possuam objetivos diferentes, querem comunicar sobre sustentabilidade e associar às suas marcas, mas de uma forma breve e leve, o que não condiz com a complexidade e profundidade do assunto.

Por isso a importância de utilizar a semiótica que entra na raiz da questão e procura evitar falhas triviais, principalmente em questões de muita abrangência.

A semiótica peirceana não deixa as empresas se perderem na associação da marca com a sustentabilidade.

\section{REFERÊNCIAS BIBLIOGRÁFICAS}

HERZOG, A. L. "A vitória do pragmatismo". in Guia Exame de Sustentabilidade. São Paulo, p. 36-43, novembro 2009.

KELLER, K. L, MACHADO, M. Gestão estratégica de marcas. Tradução: Arlete Simille Marques. São Paulo: Pearson Prentice Hall, 2005.

KOTLER, P. KELLER, K. L. Administração de marketing. Tradução: Monica Rosenberg, Brasil Ramos Fernandes, Cláudia Freire. São Paulo: Pearson Prentice Hall, 2006.

LENCASTRE, P. CORTE-REAL, A. "Um triângulo da marca para evitar a branding myopia: contribuição da semiótica para um modelo integrado de compreensão da marca”. in Organicom Revista Brasileira de Comunicação Organizacional e Relações Públicas. Ano 4, Número 7, p. 98-113, 2º semestre 2007.

PEREZ, M. C. Signos da marca: expressividade e sensorialidade. São Paulo: Pioneira, 2004.

PORTER, M. Vantagem Competitiva. Rio de Janeiro: Campus, 1989.

RACHMAN, D. J. Varejo: estratégia e estrutura. São Paulo: Atlas, 1973.

SANTAELLA, L. Semiótica Aplicada. São Paulo: Pioneira Thomson Learning, 2004. 
A importância da semiótica aplicada na marca de varejo de Flávia Cristina Martins Mendes

Artigo recebido: 15/11/2011

Artigo aprovado: 20/03/2012 